UK innovation centre fails to meet some expectations

London. As the government of British Prime Minister John Major looks to 'technology foresight' (see below) for ways of stimulating the commercial exploitation of science, rumblings of unease are being heard about a major initiative launched by the government of his predecessor, Mrs Margaret Thatcher, to achieve precisely this goal.

The Centre for Exploitation of Science and Technology (CEST) was set up in 1988 at the explicit recommendation of the government Advisory Committee on Applied Research and Development. It operates as a think tank jointly sponsored by government and industry, exploring the market potential for new science-based products.

But a confidential survey of companies represented on the council has found that about half of those interviewed would like to see a better return on their investment. All said they would have some difficulty in justifying renewing their subscription.

The survey was carried out by an outside consultant. It reports that most of the companies who support CEST are enthusiastic about the work it carries out, benefiting in particular from involvement in individual projects which had increased their contact with others in the field.

But one-third of 82 individuals contacted from among the council and working group members claimed that CEST was not strong enough politically, and 90 per cent said that they viewed CEST as "badly deficient in communications".

Companies belonging to CEST come from the top ranks of British industry, and include names such as Rolls Royce, Glaxo and ICI. Most currently pay a membership fee of about $£ 58,000$ a year, and additional support comes from the government. The Office of Science and Technology, for example, provides funding of $£ 116,000$ a year out of the science budget.

One of CEST's best known reports was one published three years ago putting the case for the creation of so-called Faraday centres, to provide a focus for interaction between the academic world and industry. The idea was enthusiastically endorsed by the Tory government shortly before the general election in 1992. However it was dropped after the election by the President of the Board of Trade, Michael Heseltine, on the grounds that new institutional structures were unnecessary.

Apart from this, however, CEST appears to have made less of an impact on major policy debates than some of its supporters had hoped. It also raised some eyebrows with its submission to the government during preparations for last year's science white paper (policy document). This suggested that government funds for basic research be channelled through an independent Industrial Technology Council, and described the undirected use of public resources to support science and technology as "a luxury we cannot afford".

CEST has not grown as fast as it had hoped. Last year's annual accounts report an operating loss of $£ 300,000$ on turnover of $£ 1.7$ million; part of this was due to a dispute with the Inland Revenue over VAT payments, but CEST also admitted that income had not met expectations "due to the difficulty of finding new member companies". Since then, two of its member companies - British Telecom and Thorn/ EMI - have resigned, increasing the financial pressure on the organization.

Bob Whelan, CEST's director who was formerly the marketing manager of the consulting firm P A Technology, denies that the organization is in difficulties. He declined to comment on the contents of the report, on the basis that its conclusions are confidential. But he acknowledged that the report identified "areas that are going well," as well as "some that we need to do work on."

Sir John Fairclough, the chairman of CEST and formerly Mrs Thatcher's chief scientific adviser, says that a working group had now been set up which was likely to suggest that CEST focus more on strategic issues. Such a move which could mean relatively less emphasis on practical topics of interest to only a few of its members.

According to one observer, CEST has suffered from ambiguity over whether it is primarily a government or a private sector initiative. Whether technology foresight will become vulnerable to the same charges remains to be seen.

David Dickson
London. Britain's Office of Science and Technology (OST) has moved to strengthen its links with the private sector by appointing five industrial scientists to head specialist 'technology foresight' panels, and a theoretical physicist turned management consultant to the post of part-time chairman of the Economic and Social Research Council (ESRC).

The industrial scientists will head five of fifteen panels whose details were released on Monday by William Waldegrave, the cabinet minister responsible for science. Each will cover a specific sector of social activity, ranging from transport, through leisure and education to defence and aerospace.

According to William Stewart, the gov-

\section{Women 'should fill a quarter of top scientific posts'}

London. Britain's Office of Science and Technology (OST) has been urged to set up a 'development unit' to oversee the interests of women scientists. The government has also been told that it and other employers should aim at seeing women occupy one quarter of all public appointments and senior positions in science, engineering and technology by the end of the decade.

Jean Balfour, the deputy chairman of the Women in Science, Engineering and Technology committee, which presented its recommendations to the government last week in a report entitled The Rising Tide, said a development unit in the OST would be a key focus for the government in this area.

The panel suggested that the unit should quantify the benefits of 'women-friendly' practices, such as the provision of crèches, flexible working hours and working for employers from home.

"This report is really a first step looking towards the future," said Balfour last week. "Women scientists and engineers have particular problems, as the period when their careers are at a crucial stage often coincides with the time that they are occupied with bringing up families."

But problems may take root much earlier, with fewer girls opting to continue with science subjects after completing the compulsory science syllabus at 16 . The report points to the success of the Scottish system, under which pupils normally take up to five subjects in a more advanced examination at the age of 17 .

In 1991 girls achieved almost half the total number of passes in mathematics and chemistry in the Scottish examinations, compared to 36 per cent and 41 per cent respectively in England.

Fiona Gammie

\title{
Industrialists to head UK foresight panels
}

ernment's chief scientific adviser and one of the architects of its foresight initiative, the panels will prepare reports that will then be used to "inform" government decisions about the allocation of research resources.

Stewart says that the OST has decided to go for an across-the-board approach, rather than starting more modestly as some had suggested with a few experimental foresight exercises, because "we felt it much better to commit ourselves to a major involvement."

The launching of the technology foresight panels coincides with the news that Bruce Smith, once an adviser to NASA on the Apollo space programme, is to be the new chairman of the ESRC. 